\title{
Birthday of Konstantin Vsevolodovich Grigorovich
}

DOI: $10.1134 / \mathrm{S} 106193481109005 \mathrm{X}$

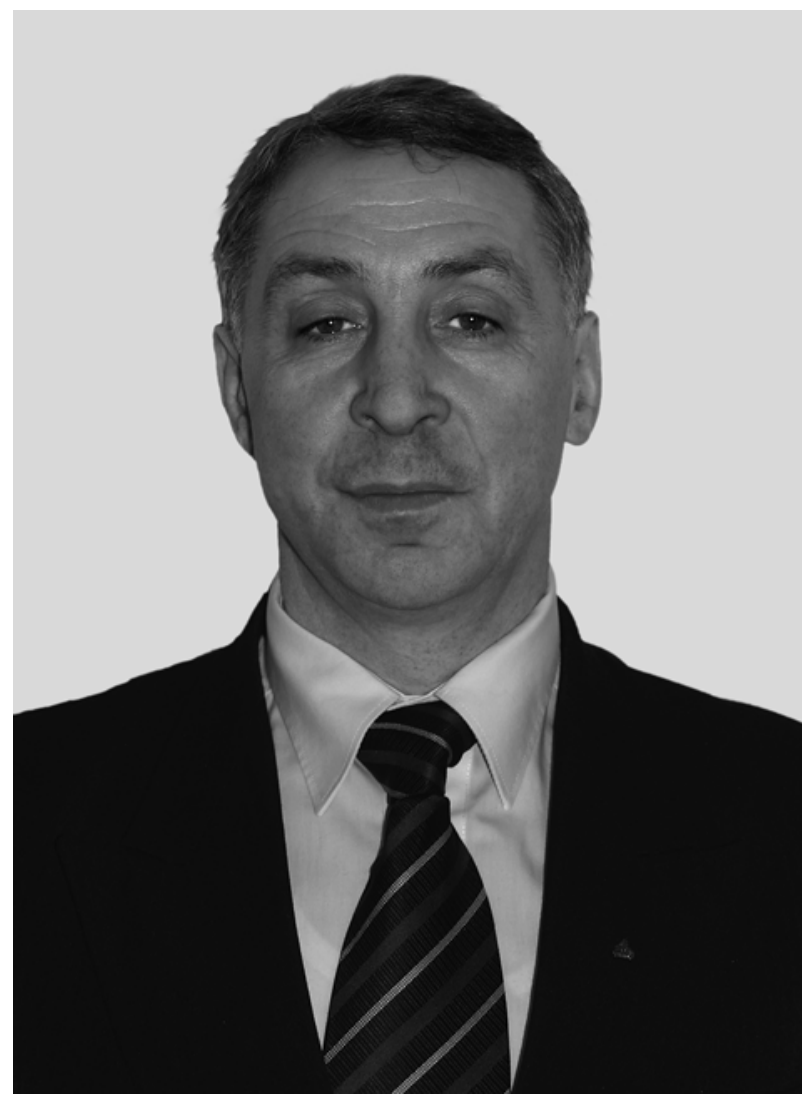

September 27, 2011 is the 60th birthday of Konstantin Vsevolodovich Grigorovich, Corresponding Member of the Russian Academy of Sciences, Doctor of Technical Sciences, and Head of the Laboratory of Material Diagnostics of the Baikov Institute of Metallurgy and Materials Science of the Russian Academy of Sciences.

Grigorovich is an outstanding scientist in metallurgy and analytical chemistry. His best-known works are devoted to the fractional determination of gases in metals by high-temperature extraction. As one of the creators of this method, Konstantin Vsevolodovich developed the theoretical basics, physicochemical models, algorithms, metrological provision, and analytical procedures. The method has gained wide recognition. Professor Grigorovich has successfully combined his analytical studies with the application of analytical methods for the sophistication of the technology of metallurgical processes. His ideas have found applications in almost all large factories of ferrous metallurgy in Russia.

In recent years, Grigorovich has significantly expanded his field of scientific interests. He performed original studies on the application of glow discharges in atomic spectrochemical analysis and developed procedures for determiing oxygen in finely divided nanomaterials of some other objects. Grigorevich heads a Division at the State Technological University Moscow Institute of Steel and Alloys; supervises diploma and postgraduate works; and is a member of the Scientific Council on Analytical Chemistry of the Russian Academy of Sciences and a member of editorial boards of the journals Zavodskaya Laboratoriya: Diagnostika Materiallov, Elektrometallurgiya, and Rasplavy. Professor Grigorovich is the author of more than 200 scientific works.

Konstantin Vsevolodovich is an excellently educated, well-rounded, and benevolent person, as well as a highlyesteemed authority among both scientists and industrial workers. He has generated huge possibilities in the development of the analytical chemistry of metals.

In the jubilee year of Professor Grigorovich, the editorial board, colleagues, and staff of Zhurnal Analiticheskoi Khimii congratulate Konstantin Vsevolodovich on his birthday and wish him new successes and well being. 